\title{
Factors Influencing Cohabitation Among Undergraduate Students of Federal University of Technology Minna, Niger State, Nigeria: Implications for Counselling
}

\author{
Dr. John Jiya \\ Department of Counselling Psychology, Ibrahim Badamasi Babangida University, Lapai. \\ Niger State, Nigeria \\ Alhassan, Daniel Zhiri \\ Student Affairs Division, Federal University Of Technology,Minna
}

\begin{abstract}
The study investigated factors responsible for cohabitation among students of Federal University of Technology Minna, Niger State, Nigeria. Two research questions were formulated to guide the study. Descriptive survey research design was adopted for this study. A sample size of 285 was obtained using proportionate random sampling technique for students. The instrument used for data collection was the researcher designed questionnaire. Frequencies were counted and percentages were computed for the demographic categories. Mean and Standard Deviation were used to answer the research questions. Decisions on the research questions were based on the resulting means score interpreted relative to the concept of real lower and upper limits of numbers. The findings in terms of prevailing factors of cohabitation include: Peer pressure, inadequate hostel accommodation, poverty, access to pornographic materials and inability to manage sexual urges among others. Some of the recommendations include; concerted effort should be made to provide additional on-campus hostel accommodation/facilities, student orientation should be organized as soon as new students resume, rules regulating students' conduct in hostel accommodation should extend to off-campus accommodation particularly in cultures that frown at cohabitation and timely organization of seminar and workshops for students and parents on reproductive health, social skills, sporting activities and distracting effect of cohabitation.
\end{abstract}

Keywords: undergraduate students, cohabitation, factors, counselling.

DOI: $10.7176 / \mathrm{JEP} / 10-9-02$

Publication date:March $31^{\text {st }} 2019$

\section{INTRODUCTION}

The policy of Nigeria Government on mass education as exemplified by the launching of Universal Primary Education (UPE) in 1976 and the Universal Basic Education (UBE) in 2000 has resulted in upsurge of student population at all levels of Nigerian education system. Part of the consequences of this policy is shortage of hostel accommodation in tertiary institutions resulting in geometric increase in off campus accommodation. In some Universities like the Federal University of Technology, Minna, you have less that $25 \%$ of student population on campus hotel. The advantage of hostel accommodation is that the University is able to positively influence daily activities of studentship in terms of access to utilities, security, hygiene, whole students' interpersonal relationship etc

Off-campus accommodation is so common now that in many Universities, nearby communities are called 'students' villa'. The increase in the number of youths of opposite sex living together under the camouflage of lack of hostel accommodation in Nigeria higher institutions of learning is alarming. This act is referred to as cohabitation. Cohabitation is described as the situation in which two persons of opposite sex, without being conventionally or formally wedded, reside mutually and enjoy all or some of the values of marital relationship (Ogadima (2013, Huang, Smock, Bergstrom and Lynch (2011) . Cohabitation is defined as an intimate sexual union between two unmarried partners who share the same living quarter for a period of time. The rise in cohabitation represents one of the most significant changes in union formation patterns in many developed and developing economies. The increase in cohabitation has occurred alongside other, related, major demographic shifts, including rising levels of divorce and delay in entry into marriage and childbearing.

The purpose of this paper is to ascertain reasons for the increasing trend of cohabitation in a cultural context that frowns at close relationship between boys and girls outside marriage. University students are supposed to be culture sensitive as part of meeting public expectation of high level of civility and roundedness in human development.

Ekpenyong and Ekpenyong (2016) posited that many younger students cohabitating enter into joint living arrangement as a result of unstable partnership. Mustapha, Odebode and Adegboyega (2017) further noted that economic well-being is positively related to the odds that contribute to cohabiting. Those who choose to cohabit tend to be of slightly lower socio-economic status, more liberal, less religious and are more supportive of 
egalitarian gender roles and non-traditional family roles. College students who cohabit generally hold a positive attitude about the situation, reporting personal growth, deeper understanding of one's partner, deeper love, disclosing more and better sex lives. Svodziwa and Kuerten (2017) also found that college students who cohabit have higher level of general well-being and happiness. Cohabitation among individuals of opposite sex is a predisposing factor to the initiation of sexual activities (Ogungbanila, 2013).

The Norms Activation theory developed by Schwartz (1977) is a theory which makes it clear that personal norms can directly provide sustainable desirable behaviour. The theory sees behaviour as flowing out of thought which can be influenced by personal norms such as feelings and sense of moral obligation. This theory viewed individual as a person which could be responsible of his or her action. The action based on these norms may support the sense of self - satisfaction and pride, while those against such feelings may feel sense of guilt and unhappiness. This theory is supported by Abrahamse and Steg (2011), who agreed that each person is required to have understanding or been aware of the consequences of the behaviour exhibited and should be personally responsible for the penalty. The figure one (fig.1) shows the awareness of consequences and ascription of responsibility to personal norm lead to behaviour change. Constant awareness on the implications of cohabitation among students will help them to change their behavior positively.

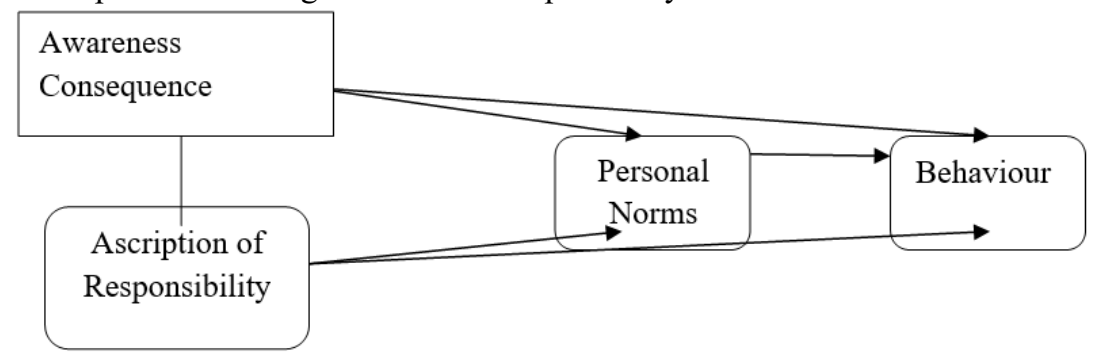

Fig 1. The Norm Activation Model. (Source; Schwartz, 1977).

The figure above implies that being aware of norms that guide personal behavior and its consequences can help a person to take responsibilities that could result to positive behavioral change.

Cohabitation results in two independent people almost like room-mates, who are sexually involved, instead of being committed to one another for the rest of their lives. Ojewola and Akinduyo (2017) lamented that students who should be engaged in serious academic pursuit often end up performing below expectation because of all these distraction. Manning and Smock (2009) corroborated this idea that the number of young adults engaging in premarital sexual behavior has increased to 60 percent in the last 20 years. Cohabitating students will often engage in unprotected sex which could result in sexually transmitted infection and the much dreaded HIV/AIDS disease (Huang, Smock, Manning, Bergstrom, and Lynch, 2011).

According to Mustapha, Odebode and Adegboyega, (2017) reported that there is an increase in the rate cohabitation among the youth especially tertiary institution students. They added that cohabitation has serious health effect on the female students who may indulge in the use of oral contraceptive in order to avoid unwanted pregnancy which may truncate their educational aspiration. Should pregnancy occur? Such female students are more likely to seek abortion as alternative. Akisukunu (2013) said that part of the implications of this is for such students to visit quack doctors and medical practitioners without adequate experience and qualification. This is more likely in view of the illegality of abortion in Nigeria. Some who frown at abortion end up giving birth to unwanted babies who may not be properly catered for by these students. Irma (2015) said cohabitation is totally against the norms and values of African society, talk less of Niger State of Nigeria that is religiously hyperactive. The situation where youth lived together especially where they do not have any family affinity is often regarded as an aberration. It is disheartening to note that while some students cohabit without the knowledge of their parents, some parents feign ignorance when they get to know.

Another factor that could influence cohabitation among students of higher institution is age. Nowadays, many students commence higher institution at very young age and as such are naïve. Adeoye, Ola and Aliu, (2012) asserts that early young adults were mostly prone to premarital sexual behavior. Cohabitation among undergraduates could also be a response to unguarded freedom, being free for the first time from parents and school authority rules and regulation in boarding house at secondary school level, they tends to enjoy the freedom, independence and less monitored by either parents or guardians. Religion is an important variable in cohabitation among undergraduates. Literature reveals that those with religions affiliations are less likely to cohabit than those without religious affiliation. Irma (2015) also observed that individuals who are religious are more inclined to positive traditional family attitudes and behaviors. They stated further that norms regarding family formation behaviours of individuals are commonly shaped and reinforced by religious institution. In addition, strong religious parents can affect their child's behaviors through guidance and supervision. The understanding that family values require children to behave in a manner not to embarrass parents may discourage cohabitation. The decline in religious commitment/piety and fanfares of religion may be partly responsible for rise in immorality. Students are 
now able to do what they desire as well as maintain membership of religious bodies without any sense of guilt.

The non-residential accommodations in many higher institutions tend to encourage this new trend of students cohabiting, unlike what was in operation in the olden times. Initially all students were accommodated within institution's halls of residence (Ekpenyong and Ekpenyong, 2016). Those students accommodated within institution's hall had rules and regulation guiding their stay. Thus within a short time, Nigerian tertiary institutions began to experience challenge of inadequate hostel accommodation because the population of students continue to grow without corresponding growth in the number of halls of residence and other physical facilities. The objective of this study is to determine factors influencing cohabitation among students of Federal University of Technology Minna with a view to providing bases for remediation through further entrenchment of counseling inspired recommendations

\section{Statement of the problem.}

Cohabitation in the higher institutions of learning across the nation has become a thing of serious concern, as the ratio of the number of undergraduate intakes to the available accommodation facilities is always in geometric progression. Government inability to provide adequate hostel accommodation is directly aggravating the tendency towards cohabitation (Ogadimma and Arisukwu, 2013). The practice where students of opposite sex live together and share things in common without any traditional or legal authorization is a contributory factor to formation of all kinds undesirable bonding patterns including cultism (Adeoye,ola and Aliyu, 2012).

Cohabitation with its attendant risk to unrestrained fun and sexual activities may cause distraction for students. This may lead to academic underachievement in view of the fact that relationship management and pseudomarriage setting requires effort and time. It can also confer (especially on boys) a false sense of accomplishment that may not relate to the primary purpose of schooling. It is on the basis of the foregoing that the study is designed to investigate the likely reasons for cohabitation among students of Federal University of Technology, Minna.

\section{Research Question}

The research question focuses on factors influencing cohabitation on the basis of perception of University students. It includes the following areas:

i. Is lack of hostel accommodation a cause of cohabitation in the University?

ii. Is poverty or lack of resources to pay for accommodation, a factor of cohabitation?

iii. Is peer pressure one of the reasons for cohabitation?

\section{Research methodology}

The study adopted descriptive survey design. The population of the study was 14,225 Students. Sample size of 285 was obtained using 2 percent proportionate random sampling technique for students.

\section{Research instrument.}

The instrument used for data collection was a researcher designed questionnaire titled Factors Influencing Cohabitation among students (FICAS). The questionnaire was divided into two sections, the first section focused on demographic characteristics and the second section focused on the factors using four Likert scale respond pattern. The instrument content validity was confirmed by experts in the field of counselling psychology of the Federal University of Technology Minna. Test-retest method was used to obtain reliability index of 0.75 using Pearson product moment correlation coefficient.

\section{Method of Data Analysis}

The data collected for the study was organized and analyzed on the basis of the research questions. Frequencies were counted and percentages computed for the demographic categories. Mean and Standard Deviation were used to answer the research questions. Decisions on the research questions were based on the resulting means score interpreted relative to the concept of real lower and upper limits of numbers as shown in Table 1. The standard deviation was used to decide on the closeness or otherwise of the respondents to the mean in their responses. Any item with standard deviation of less than 1.96 indicated that the respondents were not too far from the mean or from one another in their responses and any item having standard deviation equal or above stated value signified that respondents were too far from the mean.

Table 1: Interpretation of Four Point Scale

\begin{tabular}{llll}
\hline S/N & Scale & Point & Real and Upper Limit \\
\hline 1 & Strongly Agreed & 4 & $3.50-4.49$ \\
2 & Agreed & 3 & $2.50-3.49$ \\
3 & Disagreed & 2 & $1.50-2.49$ \\
4 & Strongly Disagreed & 1 & $1.00-1.49$ \\
\hline
\end{tabular}




\section{Descriptive Data}

Demographic information for respondents is presented in Table 2 and Table 3. The data were collected from a group of respondents such as

Table 2: Distribution of Respondents by Levels; 200, 300, 400 and 500

\begin{tabular}{llll}
\hline Category & Frequency & Percentage & Cumulative Percentage \\
\hline 200 Level & 61 & 21.40 & 21.40 \\
300 Level & 65 & 22.81 & 44.21 \\
400 Level & 82 & 28.77 & 73.98 \\
500 Level & 77 & 27.02 & 100 \\
Total & 285 & 100.00 &
\end{tabular}

The distributions of the respondents based on student's level revealed that $21.40 \%$ were 200 Levels; $22.81 \%$ were 300 Levels; $28.77 \%$ were 400 Levels and 27.02\% were 500 Levels represented in Table 2.

Table 3: Distribution of Respondents by Gender Male and Female

\begin{tabular}{llll}
\hline Category & Frequency & Percentage & Cumulative Percentage \\
\hline Male & 156 & 54.74 & 54.74 \\
Female & 129 & 45.26 & 100 \\
Total & 285 & 100.00 & \\
\hline
\end{tabular}

The distribution of respondents by gender revealed that Male Students were $54.74 \%$ and Female Students were $45.26 \%$ as represented in Table 3 .

What are the factors influencing cohabitation among students of Federal University of Technology Minna?

Table 4: Shows the mean responses of male and female students on factors influencing cohabitation among students of Federal University of Technology Minna.

\begin{tabular}{|c|c|c|c|c|c|c|}
\hline $\mathrm{S} / \mathrm{N}$ & ITEM & $\bar{X}_{1}$ & $\bar{X}_{2}$ & $\overline{\boldsymbol{X}}_{\mathrm{av}}$ & $\mathbf{S D}_{\mathrm{av}}$ & Remark \\
\hline 1 & Lack of hostel accommodation & 3.97 & 3.24 & 3.61 & 0.67 & Agreed \\
\hline 2 & Poor academic performance & 2.22 & 1.28 & 1.75 & 0.98 & Disagreed \\
\hline 3 & Financial Challenges & 3.29 & 3.07 & 3.18 & 0.34 & Agreed \\
\hline 4 & To study themselves & 1.43 & 1.68 & 1.55 & 0.54 & Disagreed \\
\hline 5 & Peer pressure & 3.62 & 3.54 & 3.58 & 0.91 & Strongly Agreed \\
\hline 6 & Poor parenting & 2.56 & 2.49 & 2.53 & 1.01 & Agreed \\
\hline 7 & Desire for sexual satisfaction & 3.65 & 3.71 & 3.68 & 1.12 & Strongly Agreed \\
\hline 8 & Flamboyant living among students & 3.05 & 3.12 & 3.09 & 0.76 & Agreed \\
\hline 9 & Social groups (Associations and club) & 2.61 & 2.54 & 2.58 & 0.87 & Agreed \\
\hline 10 & Religious activities (Fellowships/ Societies) & 1.45 & 2.34 & 1.90 & 0.21 & Disagreed \\
\hline 11 & Co-education nature of Universities & 2.63 & 2.88 & 2.76 & 0.39 & Agreed \\
\hline 12 & Ineffective counseling during secondary education & 2.89 & 2.50 & 2.70 & 0.68 & Agreed \\
\hline 13 & Newness to the environment & 1.76 & 1.45 & 1.61 & 1.11 & Disagreed \\
\hline 14 & Inadequate education on reproduction health & 1.91 & 1.57 & 1.74 & 1.05 & Disagreed \\
\hline 15 & Watching of unlicensed erotic video films & 2.76 & 2.91 & 2.84 & 0.76 & Agreed \\
\hline
\end{tabular}

$\overline{\boldsymbol{X}}_{1}=$ Mean responses of Male students: $\overline{\boldsymbol{X}}_{2}=$ Mean responses of Female Students;

$\overline{\boldsymbol{X}}_{\mathrm{av}}=$ Average Mean of Male and Female Students

Table 4: Revealed that the respondents strongly agreed with items 5 and 7 . They agreed with

Items: $1,3,6,8,9,11,12$ and 15 . But they disagreed 2, 4, 10, 13 and 14 . The standard deviation of 15 items ranges from $0.21-1.12$ each of these values was less than 1.96 indicating that the respondents mean scores were not too far from each other and was close to one another in their responses. This adds value to the reliability of the mean. The mean score agreement from standard deviation is less than 1.96 therefore the research question was upheld as stated.

\section{FINDINGS}

Factors influencing cohabitation among students of Federal University of Technology Minna include:

$>$ Inadequacy of hostel accommodation since cohabitation is not possible on campus accommodation,

$>$ Lack of resources to pay as at when due thereby creating the opportunity for students who have resources to lure poor students to stay with them. The same scenario is applicable for the growing trend of lesbianism and homosexuals

$>$ Peer pressure,

$>$ Inability to manage sexual urges or desire for sexual satisfaction,

$>\quad$ Watching of unlicensed erotic video films. 


\section{DISCUSSION OF FINDINGS}

The study shows that inadequate hostel accommodation for students influences cohabitation among students. This finding is in agreement with the study carried out by Ojewola and Akinduyo (2017), which said the University authority should provide more hostel accommodation for the students especially the female students. The hostel accommodation provided by the university should be conducive and affordable for the entire student. They furthered agreed that the provision of adequate hostel accommodation for students will significantly reduce cohabitation among students. The school authority should monitor students living off campus to curb their excessive behaviour especially regarding cohabitation. Svodziwa and Kurete (2017) also supported the finding, they lamented that lack of hostel accommodation is a serious reason why students cohabitate in tertiary institutions. Another student said, "Due to lack of accommodation, I have to live with my guy and I don't see anything wrong in it." While some cohabiting students find it difficult to live apart because of financial or academic dependency, the strong physical intimacy between them makes them think sex is love.

Peer pressure is also reason advanced by the students as factor influencing cohabitation. The majority of young people who become involved in cohabitation and premarital sex do so because of peer pressure. They look at their peers and give in to temptation, because 'everyone does it'. They do it in order to fit into peer sub-culture or avoid being laughed at and to receive affirmation/approval from their peers. In the end, cohabitation and premarital sex have become kinds of passports to acceptance in a particular age group (Ekpenyong and Ekpenyong, 2016). Barker (2007) claimed that peer pressure and community characteristics are a major factor that influences teenagers to engage in risky sexual behaviour. Teenagers that have sexually active friends or pregnant friends are likely to fall pregnant several times. Unguided and uncontrolled surfing on the Internet can expose youth to pornography online. Young people are often hooked by sexual images that they are exposed to as they surf the internet. The internet is also doing a great deal of damage when it comes to the sexual lifestyle of Nigerian youth, because some of those who are bombarded by pornography also like to put it into practice. The media focuses more and more upon the sensual. African youths are exposed to sex and related matters through the medium of newspapers, television, pornographic videos, the internet, radio and various magazines. Explicit sex videos and DVDs are sold in the open market. They also receive mixed messages from the media. In any given week, they are likely to hear contradictory messages such as 'No sex until you're married', 'No sex until you are older', 'No sex unless you're protected' or 'No sex unless you're in love' (Ekpenyong and Ekpenyong, 2016). Poverty is also a factor as attested to by the respondents. To this category of students, cohabiting helps them to reduce the cost of living in the school. They enjoy the financial support of their partner when they live together. This agrees with the position of Ogadimma (2013) who found that students from poor socio-economic background coupled with poor moral values are at risk of accepting free offer of accommodation on conditions of playing subservient roles. This is particularly so for girls who are poor to be easily accommodated by fairly well-off boys. There could be cases of girls who are sexually active and economically well-off accommodating indigent boys. This calls for social net for indigent students through scholarship and grants to reduce the effect of poverty. The present practice in Nigeria where scholarships are given to academically high performing students may not be suitable for addressing this problem especially for the imperative of the relationship between socioeconomic background and academic achievement.

\section{CONCLUSION}

The incidence of cohabitation as evident in the study is caused by factors that can be addressed without much cost or damage to the students. The study revealed that the reasons why students of Federal University Of Technology Minna engage in cohabitation is include inadequate hostel accommodation, financial challenges faced by students most especially female students, peer pressure, lack of supervision by parents under the guise that students have "grown", the use of erotic sexual film and magazine etc. This study shows that student population is generally at home with the practice, that is, even students who are not cohabiting, seem to see nothing wrong with it.

\section{Implications for Counselling}

In view of the acknowledgement of Counselling as part of school support services in Nigeria National Policy on Education (FGN 2004) which expressly admitted the relevance of counselling in resolving challenges bordering on human maladjustment. Cohabitation is seen in this study as an example of maladjustment, that is, young people trying to manage sexual challenges that are common feature of adolescent growth trend through improper heterosexual relationship. What is required is help in the form of counselling, not sympathy or acquiescence. Some of the implications of the findings for counselors include:

* Mainstreaming robust sex education into University curriculum with a view to inoculating young people against sex related challenges that are real but with their capacity to handle

* Help students appreciate the adverse effect of premarital sex on marital adjustment. For example, people who engage in regular premarital sexual activities often find it difficult to trust their spouses' fidelity. This is based on personal counseling experience particularly when such "campus couples" marry 
themselves.

* Help students understand the risk of pregnancy, denial by the males and the risk of sexually transmitted diseases

* Create awareness about cohabitation as a distraction that may result to academic underachievement

In sum, it behooves on school counselors to constantly re-examine and re-jig their professional effectiveness particularly for societies where their recognition as a professional body is still a challenge.

\section{RECOMMENDATIONS}

Based on the findings of the study, the following recommendations were made:

* Concerted effort should be made to provide adequate on-campus hostel facilities to accommodate growing student population in higher institutions. In this regard, accommodation of virtually all the students who are not married should be part of requirement for accreditation of courses/programmes.

* Functional Counselling unit should be promoted. It is not enough to appoint counsellors, there should be conducive working environment in terms of appropriate counsellor/student population ratio, funding of the center for purposes of access to good psychological tests, capacity for workshops and seminars etc

* Collaboration between parents and the University should be nurtured so that the University can justify the need for parental supervision of undergraduates which is poorly (if at all) done now.

* Campus radio should be used more effectively to promote healthy relationships across gender on campus

* There should be collaboration between University authority and Land Lords of off-Campus accommodation facilities so that rules and disciplinary measures applicable to on-campus students can be extended to off-campus students. This will require awareness creation and collaboration with student union bodies.

\section{REFERENCES.}

Abrahamse, W., and Steg, L. (2011). Factors related to household energy use and intention reduces it: The role of psychological and socio-demographic variables. Human Ecology Review, 18 (1), 30 - 40.

Adeoye, A. O. Ola, O. and Aliu, B. (2012) Prevalence of premarital sex and factors influencing it among students in a private tertiary institution in Nigeria. International Journal of Psychology and Counselling 4 (1), 6-9.

Barker, P. (2007). Teenagers, social support and help-seeking behaviour: An international literature review and programme consultation with recommendations for action. Retrieved on April 24, 2018 from http://whqlibdoc.who.int/publications/2007/9789241595711_eng.pdf

Ekpenyong, N. S. and Ekpenyong, A. S. (2016). Perceived Factors Influencing Premarital Sexual Practice among University Students in Niger Delta University, Bayelsa State, Nigeria. Canadian Social Science, 12 (11): 79 88.

Elkonin, D. S., and Sandison, A. (2006). Mind the gap: Have the registered counsellors fallen through? South African Journal of Psychology, 36, 598-612

Federal Republic of Nigeria (2004). National Policy on Education. Lagos: NERDC Press.

Green, J. C. (2007). Mixed methods in social inquiry. New York: Wiley.

Huang, P., Smock, P., Manning, W., Bergstrom, and Lynch, C. (2011). He says, she says: Gender and cohabitation. Journal of Family Issues, 32, 876-905.

Irma L. P. (2015).The Impact of Peer Relations in the Academic Process among Adolescents. Mediterranean Journal of Social Sciences 6 (1)127-132

Manning, W. D. and Smock, P. J. (2009). Divorce-proofing memage: Young adults views on the connection between cohabitation and marital longevity: NCFR Report, 54: F13-F15.

Mustapha, M. L., Odebode, M. D. and Adegboyega, L. O. (2017) Impact of Premarital Cohabitation on Marital Stability as Expressed by Married Adults in Ilorin, Nigeria. Asia Pacific Journal of Multidisciplinary Research 5( 1),

Ogadimma, C. A. (2013) Cohabitation among University of Ibadan Undergraduate Students Research on Humanities and Social Sciences 3(5)185-192

Ojewola, F. G. and Akinduyo, T. E. (2017) Prevalence and Factors Responsible for Cohabitation among Undergraduates of Adekunle Ajasin University, Ondo State, Nigeria. American Journal of Educational Research, 5( 6) 650-654

Paisley, O., and McMahon, H. G. (2001). School counselling for the 21st century: Challenges and Opportunities. Professional School Counselling, 5(2), 106-110

Schwartz, S. (1977). Normative Influences on Altruism. Advances in Experimental Social Psychology, 10 (1), $222-$ 279. 
Scott, J. (2000). Rational choice theory. In G. Browning, A. Haldi and F. Webster (Eds) Understanding contemporary society: Theories of the presents. Retrieved on April 12, 2018 from http://www.soc.iastate.edu

Svodziwa, M. and Kurete, F. (2017) Cohabitation among Tertiary Education Students: An Exploratory Study in Bulawayo. Human Social Studies, vol. VI, (1) 138-148 